\title{
Functional evaluation with microperimetry in large idiopathic macular holes treated by a free internal limiting membrane flap tamponade technique
}

Peirong Huang ${ }^{1,2+}$, Hong Wang ${ }^{1,2 \dagger}$, Fenge Chen ${ }^{1}$, Jieqiong Chen ${ }^{1}$, Yifan $\mathrm{Hu}^{1}$, Junran Sun ${ }^{1}$, Jingyang Feng ${ }^{1,3^{*}}$ (D) and Hong Zhu $\mathrm{H}^{1,2,3}$

\begin{abstract}
Background: Free internal limiting membrane (ILM) flap tamponade technique is an alternative choice for treating large idiopathic macular holes (IMHs). However, the functional recovery related to this surgical approach is not well-characterized. This study aimed to evaluate morphological and microperimetric outcomes 6 months after free ILM flap tamponade technique for large IMHs.

Methods: Twenty-two patients (22 eyes) with large IMHs (minimal diameter $>400 \mu \mathrm{m}$ ) were retrospectively enrolled in this study. All patients underwent 23-gauge pars plana vitrectomy with ILM peeling and free ILM flap tamponade procedures. Snellen best-corrected visual acuity (BCVA), optical coherence tomography (OCT), and MP-1 microperimetry were measured at baseline and 6 months after surgery. Associations of postoperative BCVA with retinal sensitivity were detected.

Results: Macular hole closure was achieved in 21 eyes (95.5\%). Dislodgement of free ILM flap was found in non-closed eye. Mean logMAR BCVA improved from $1.10 \pm 0.33$ at baseline to $0.67 \pm 0.32$ at 6 months postoperatively $(P<0.001)$. The mean overall macular sensitivity and foveal fixation stability increased respectively from $8.58 \pm 3.05 \mathrm{~dB}$ and $65.64 \pm 17.28 \%$ before surgery to $11.55 \pm 2.72 \mathrm{~dB}$ and $78.59 \pm 13.00 \%$ at 6 months after surgery $(P<0.001)$. The mean change in foveal sensitivity (within $2^{\circ}$ ) was significantly greater than the change achieved for peri-foveal sensitivity $\left(2^{\circ}\right.$ to $\left.10^{\circ}\right)$ by $1.50 \pm 2.62 \mathrm{~dB}(P=$ 0.014). Linear regression analysis showed that postoperative logMAR BCVA was significantly associated with duration of symptom $(B=0.063, P=0.001)$, preoperative logMAR BCVA $(B=0.770, P=0.000)$, preoperative peri-foveal $(B=-0.065, P=$ 0.000 ) and foveal sensitivity $(B=-0.129, P=0.000)$. Moreover, multiple regression model revealed that preoperative foveal sensitivity was independently associated with postoperative logMAR BCVA $(B=-0.430, P=0.040)$.

Conclusions: Vitrectomy combined with ILM peeling and free ILM flap tamponade technique results in effective morphological and functional recovery for large IMHs. Preoperative foveal sensitivity might be a prognostic indicator for postoperative BCVA.
\end{abstract}

Keywords: Idiopathic macular hole, Microperimetry, Internal limiting membrane, Foveal sensitivity, Fixation stability

\footnotetext{
*Correspondence: ophthal_feng@163.com

${ }^{+}$Peirong Huang and Hong Wang are joint first authors

'Department of Ophthalmology, Shanghai General Hospital (Shanghai First

People's Hospital), Shanghai Jiao Tong University School of Medicine, No.100

Hai Ning Road, Shanghai 200080, China

${ }^{3}$ Shanghai Engineering Center for Visual Science and Photomedicine,

Shanghai, China

Full list of author information is available at the end of the article
}

C C The Author(s). 2020 Open Access This article is licensed under a Creative Commons Attribution 4.0 International License, which permits use, sharing, adaptation, distribution and reproduction in any medium or format, as long as you give appropriate credit to the original author(s) and the source, provide a link to the Creative Commons licence, and indicate if changes were made. The images or other third party material in this article are included in the article's Creative Commons licence, unless indicated otherwise in a credit line to the material. If material is not included in the article's Creative Commons licence and your intended use is not permitted by statutory regulation or exceeds the permitted use, you will need to obtain permission directly from the copyright holder. To view a copy of this licence, visit http://creativecommons.org/licenses/by/4.0/ The Creative Commons Public Domain Dedication waiver (http://creativecommons.org/publicdomain/zero/1.0/) applies to the data made available in this article, unless otherwise stated in a credit line to the data. 


\section{Background}

Idiopathic macular holes (IMHs) always affect middleaged and elderly people and cause severe central vision impairment $[1,2]$. Standard vitrectomy combined with the internal limiting membrane (ILM) peeling technique has been reported to achieve an excellent closure rate for macular holes with diameters smaller than $400 \mu \mathrm{m}$ [3]. However, large macular holes (minimum diameter $>$ $400 \mu \mathrm{m}$ ) are less likely to close after a classic vitrectomy $[4,5]$. Although, several modified techniques have been introduced [6-8], the surgical procedures for large, recurrent or refractory macular holes have not yet reached a common consensus.

The free ILM flap tamponade or insertion technique is an effective and relative handy operation for large macular holes $[9,10]$. This procedure is easily conducted and could be a remedy in case inverted ILM flap cracks accidently occur or ILM around the hole has already been removed. Although satisfactory anatomical results have been achieved, the effect of tamponade technique on retinal functional restoration is controversial. It is considered that the tamponade of ILM flap inside the macular hole may cause ellipsoid zone defects and affect neural retina recovery [11]. Thus, a deeper investigation of macular function after ILM tamponade surgery is needed and has important clinical significance.

Since best-corrected visual acuity (BCVA) reflects basic visual function, most studies related to ILM tamponade surgery mainly focused on visual acuity measurements. Very few researches have reported the foveal sensitivity when the free ILM flap tamponade has been used to treat large IMHs. Microperimetry, which comprises an automatic real-time tracking system to compensate eye movements, offers subregional retinal sensitivity and fixation assessments in precise location on fundus imaging [12]. Microperimetry has already been shown to achieve good efficacy and provide more detailed information of macular function in normal people or patients with macular disorders [13]. Moreover, it has been found that retinal sensitivity is more related than BCVA to the reading ability in patients with fundus diseases $[14,15]$. Therefore, the purpose of this present study was to evaluate not only morphology but also retinal sensitivity and fixation stability before and at 6 months after vitrectomy combined with ILM peeling and free ILM flap tamponade procedures for large IMHs.

\section{Methods}

This retrospective case-series study included 22 patients (22 eyes) with large IMHs (Stage III or Stage IV, minimum diameter $>400 \mathrm{um}$ ) who underwent 23-gauge pars plana vitrectomy (PPV) with ILM peeling, free ILM tamponade and fluid-air exchange at Shanghai General Hospital from November 2016 to December 2017. All patients were followed up for at least 6 months after surgery. This study was approved by the ethics committee of Shanghai General Hospital and adhered to the tenets of the Declaration of Helsinki.

All patients underwent comprehensive ophthalmological examinations before and at 6 months after surgery. The examinations included Snellen BCVA, optical coherence tomography (OCT, Heidelberg, Germany), and MP-1 microperimetry (NIDEK, NAVIS Software 3.6.4, Gamagori, Japan).

\section{Patient eligibility}

Inclusion criteria: 1) patients with idiopathic macular holes; 2) minimal hole diameter greater than $400 \mu \mathrm{m}$; and 3) follow-up longer than 6 months.

Exclusion criteria: 1) any other retinal disease; 2) high myopia with a refractive error of more than -6.00 dioptres or an axial length longer than $26 \mathrm{~mm}$; 3) server cataract; 4) a history of previous vitreoretinal surgery; and 5) severe systemic disease.

\section{Microperimetry evaluation}

MP-1 microperimetry was conducted in a dark room. After pupil dilation (1\% tropicamide), microperimetry was performed in the eye, and the contralateral eye was patched. Macular sensitivity was tested in a program implemented in Macular $10^{\circ}$ that consisted of 40 points arranged in 3 concentric circles $\left(2^{\circ}, 6^{\circ}\right.$ and $\left.10^{\circ}\right)$. Goldmann III stimuli $\left(10 \mathrm{~cd} / \mathrm{m}^{2}\right)$ randomly presented for a duration of 200 milliseconds on a $1.27 \mathrm{~cd} / \mathrm{m}^{2}$ background. Sensitivity ( $\mathrm{dB}$, decibels) was assessed using a 4-2 staircase strategy ranging from $0 \mathrm{~dB}$ to $20 \mathrm{~dB}$ in $2 \mathrm{~dB}$ steps. The mean overall macular sensitivity was calculated as the average recognized threshold of 40 points within $10^{\circ}$ of the centre. The mean foveal sensitivity and mean perifoveal sensitivity were indicated as points within $2^{\circ}$ of the centre and points within $2^{\circ}$ to $10^{\circ}$. Quantitative foveal fixation stability was measured as the percentage of fixation points within $2^{\circ}$ of the centre.

\section{Surgical procedure}

A standard 3-port 23-gauged PPV was conducted by the same surgeon using a Constellation device (Alcon, Fort Worth, TX). After core vitrectomy, the posterior hyaloid was removed from the retina with the assistance of triamcinolone acetonide (TA, $2.5 \mathrm{mg} / \mathrm{ml}$ ), and a complete vitrectomy was performed at the peripheral vitreous base. Any macular epiretinal membrane was removed if present. Then, indocyanine green (ICG) solution $(1.5 \mathrm{mg} / \mathrm{ml})$ was applied to stain the ILM around the macular hole within the arcade. The ILM was peeled around the hole to a diameter of approximately three optic disk diameters. Suitable pieces of ILM were chosen by the surgeon and placed inside the macular hole. The position of free ILM flap was retained by tucking and trapping the edge of 
pieces into the macular hole using intraocular forceps. The size of the ILM used for tamponade in each patient depended on the macular hole diameter. After confirmation that the transplanted ILM flap was inside the macular hole, abundant fluid-air exchange was slowly performed using sterilized air. If there was air leaking through any of the three incisions, a transscleral suture was applied. All patients were required to maintain a facedown position for at least 3 days after surgery.

\section{Statistical analysis}

The BCVA was converted to the logarithm of the minimum angle of resolution (logMAR). Changes in $\log$ MAR BCVA between before and after surgery were analysed using the Wilcoxon signed-rank test. Preand postoperative retinal sensitivities were analysed using the paired t-test. Linear regression analysis was performed to investigate the relationship between postoperative logMAR BCVA and other simple variables such as retinal sensitivity. Multivariate regression analysis with backward stepwise method was performed to assess the influence of variables on postoperative logMAR BCVA. All statistical analyses were performed using SPSS 21.0 for Windows. A $P$ value of $<0.05$ was considered to be statistically significant.

\section{Results}

\section{Baseline characteristics}

Twenty-two eyes of 22 patients (5 men and 17 women) with Stage III $(n=16,72.7 \%)$ and Stage IV $(n=6,27.3 \%)$ IMHs were enrolled and analysed in this study. Table 1 shows the patient characteristics and baseline clinical data. The average age of the patients was $62.41 \pm 8.13$ years old (range: $43 \sim 78$ years old). The mean baseline $\log$ MAR BCVA of the study eye was $1.10 \pm 0.33$. The mean minimum diameter (MD) of IMHs was $592.12 \pm$ $165.76 \mu \mathrm{m}$. The mean basal diameter of IMHs was $1008.04 \pm 262.72 \mu \mathrm{m}$. At the time of surgery, 6 eyes (27.3\%) were pseudophakic.

\section{Morphologic and visual outcome}

At 6 months after surgery, the macular hole was closed in 21 eyes (95.5\%). SD-OCT images showed that the fovea was filled with amorphous tissues (Fig. 1). In one unclosed eye, the macular hole showed a flat and open configuration. The mean study eye logMAR BCVA improved significantly from $1.10 \pm 0.33$ before surgery to $0.67 \pm 0.32$ at 6 months postoperatively $(P<0.001)$. An improvement of at least two lines was observed at the 6-month follow-up in 16 eyes (72.7\%). No complications, including high intraocular pressure, endophthalmitis, or retinal detachment, were observed in any cases at the last follow-up.

\section{Microperimetry outcome}

Microperimetry was assessed preoperatively and 6 months postoperatively in the 22 patients. The mean overall macular sensitivity within $10^{\circ}$ of the centre was $8.58 \pm$ $3.05 \mathrm{~dB}$ before surgery and $11.55 \pm 2.72 \mathrm{~dB}$ at 6 months after surgery $(t=7.176, P<0.001)$. The mean foveal sensitivity within $2^{\circ}$ of the centre improved from $3.39 \pm 1.98 \mathrm{~dB}$ preoperatively to $7.55 \pm 2.92 \mathrm{~dB}$ postoperatively $(\mathrm{t}=$ 10.700, $P<0.001)$. The mean peri-foveal sensitivity within $2^{\circ}$ to $10^{\circ}$ improved from $9.88 \pm 3.48 \mathrm{~dB}$ to $13.07 \pm 2.22 \mathrm{~dB}$ $(\mathrm{t}=5.465, P<0.001)$. The mean change in foveal retinal sensitivity (within $2^{\circ}$ ) was significantly greater than the mean change in peri-foveal retinal sensitivity $\left(2^{\circ}\right.$ to $\left.10^{\circ}\right)$ by $1.50 \pm 2.62 \mathrm{~dB}(\mathrm{t}=2.686, P=0.014)$.

The foveal fixation stability, calculated as the percent of fixation points within $2^{\circ}$ of the centre, had increased in 20 eyes (90.9\%) and remained equal in 2 eyes (9.1\%) at 6 months postoperatively. The average foveal fixation stability was $65.64 \pm 17.28 \%$ before surgery and $78.59 \pm$ $13.00 \%$ at 6 months after surgery $(\mathrm{t}=7.125, P<0.001)$.

\section{Association outcome}

The linear regression analysis of simple variables revealed that 6-month postoperative $\log \mathrm{MAR}$ BCVA was significantly associated with duration of symptom $(B=0.063, P=$ $0.001)$, preoperative $\log$ MAR BCVA $(B=0.770, P=0.000)$, preoperative peri-foveal $(B=-0.065, P=0.000)$ and foveal sensitivity $(B=-0.129, P=0.000)$. Furthermore, multiple regression model with backward stepwise method showed that preoperative foveal sensitivity was independently associated with postoperative logMAR BCVA $(B=-0.430, P=$ 0.040) (Table 2).

\section{Discussion}

Our study supports the efficacy of the free ILM flap tamponade technique for the treatment of eyes with large IMHs. At 6 months postoperatively, we found that 1) a high closure rate and significant BCVA improvement were achieved; 2) the mean overall macular sensitivity had significantly increased, with the foveal area within $2^{\circ}$ of centre mostly increased; 3 ) foveal fixation stability had improved; and 4) preoperative foveal sensitivity was independently associated with postoperative logMAR BCVA.

With the modern standard of pars plana vitrectomy performed with the ILM peeling and gas tamponade, small IMHs achieved a good anatomical result. However, relatively low closure rates (50 to $80 \%$ ) and unsatisfactory functional outcomes still existed in large macular holes $(\mathrm{MD}>400 \mu \mathrm{m})$ [16]. Currently, several updated techniques, including the inverted ILM flap covering technique and the ILM flap insertion manoeuvre, have been reported to achieve a satisfactory closure rate [17, 18]. The ILM insertion technique, which uses free internal limiting membrane flap tamponade in macular holes, was 
Table 1 Baseline characteristics and 6-month postoperative results of all cases $(n=22)$

\begin{tabular}{|c|c|c|c|}
\hline Characteristics & Baseline $(n=22)$ & 6-month $(n=22)$ & $\boldsymbol{P}$-value \\
\hline \multicolumn{4}{|l|}{ Age (years) } \\
\hline Mean \pm SD & $62.41 \pm 8.13$ & - & - \\
\hline Range & $43 \sim 78$ & - & - \\
\hline \multicolumn{4}{|l|}{ Gender } \\
\hline Male, n (\%) & $5(22.7)$ & - & - \\
\hline Female, n (\%) & $17(77.3)$ & - & - \\
\hline \multicolumn{4}{|l|}{ Side } \\
\hline Right, n (\%) & $12(54.6)$ & - & - \\
\hline Left, n (\%) & $10(45.4)$ & - & - \\
\hline \multicolumn{4}{|c|}{ Duration of symptoms (months) } \\
\hline Mean \pm SD & $7.77 \pm 3.09$ & - & - \\
\hline Range & $3 \sim 14$ & - & - \\
\hline \multicolumn{4}{|l|}{ IMH stage } \\
\hline Stage 3 & 16 & - & - \\
\hline Stage 4 & 6 & - & - \\
\hline MD of IMH $(\mu \mathrm{m})$ & $592.12 \pm 165.76$ & - & - \\
\hline BD of IMH $(\mu \mathrm{m})$ & $1008.04 \pm 262.72$ & - & - \\
\hline \multicolumn{4}{|l|}{ BCVA $(\log M A R)^{*}$} \\
\hline Mean \pm SD & $1.10 \pm 0.33$ & $0.67 \pm 0.32$ & $P<0.001$ \\
\hline \multicolumn{4}{|l|}{ Macular sensitivity $(\mathrm{dB})^{\#}$} \\
\hline Overall (within $10^{\circ}$ ) & $8.58 \pm 3.05$ & $11.55 \pm 2.72$ & $\mathrm{t}=7.176, P<0.001$ \\
\hline Peri-foveal $\left(2^{\circ}\right.$ to $\left.10^{\circ}\right)$ & $9.88 \pm 3.48$ & $13.07 \pm 2.22$ & $\mathrm{t}=5.465, P<0.001$ \\
\hline Foveal (within $2^{\circ}$ ) & $3.39 \pm 1.98$ & $7.55 \pm 2.92$ & $\mathrm{t}=10.700, P<0.001$ \\
\hline Foveal fixation (\%) ${ }^{\#}$ & $65.64 \pm 17.28$ & $78.59 \pm 13.00$ & $\mathrm{t}=7.125, P<0.001$ \\
\hline
\end{tabular}

$\mathrm{IMH}=$ idiopathic macular hole, $\mathrm{MD}=$ minimum diameter, $\mathrm{BD}=$ basal diameter, $\mathrm{BCVA}=$ best corrected visual acuity, logMAR = logarithm of the minimum angle of resolution

"Wilcoxon signed rank test, compared with baseline; "paired t test, compared with baseline

primarily employed by Morizane et al. [19] for refractory or recurring eyes with macular holes. Based on optimal surgical outcomes, De Novelli et al. [20] employed this technique in initially large macular holes or chronic macular hole surgery with a high successful rate. Compared with inverted ILM flap, this tamponade technique has superiority when the foveal ILM has already been peeled or if the inverted ILM flap detaches from the edge of macular hole during the surgery. This technique could be used in large macular holes or as an alternative remedy in the above circumstances. The crucial point of this surgical procedure is to prevent the dislodging of the free ILM flap from the hole. In our surgery, we used intraocular forceps to trap the margin of free ILM sheet under the edge of macular hole and performed very slow fluid-air exchange to preserve the pieces inside the macular hole. Additionally, in another study, deuteroxide was injected over the free flap for stabilization [21]. In our study, 21 eyes (95.5\%) achieved hole closures without loss of dislodging of the ILM flaps. The fovea filled with amorphous tissues represented a relatively normal contour. Comparatively, a former study revealed a similar closure rate $(96.0 \%)$ in large macular hole patients who underwent inverted ILM flap surgery [22]. Our study suggested a relatively satisfying option for surgeons.

The recovery of visual acuity after flap tamponade technique was confirmed in our study. Our baseline and 6-month-postoprerative BCVA is comparable with a previous large-size multicentre research related to inverted ILM flap technique [23]. The research showed that the mean $\log$ MAR BCVA improved from preoperative $1.05 \pm 0.31$ to $0.57 \pm 0.33$ at 6 months postoperatively in extra-large macular holes $(\mathrm{MD}>550 \mu \mathrm{m})$, and from $1.14 \pm 0.36$ to $0.73 \pm 0.35$ in super extra-large macular holes $(\mathrm{MD}>700 \mu \mathrm{m})$. The relative worse baseline and postoperative BCVA in our study might attribute to the lens status and duration of symptom. As in previous research, cataract surgery was performed simultaneously 

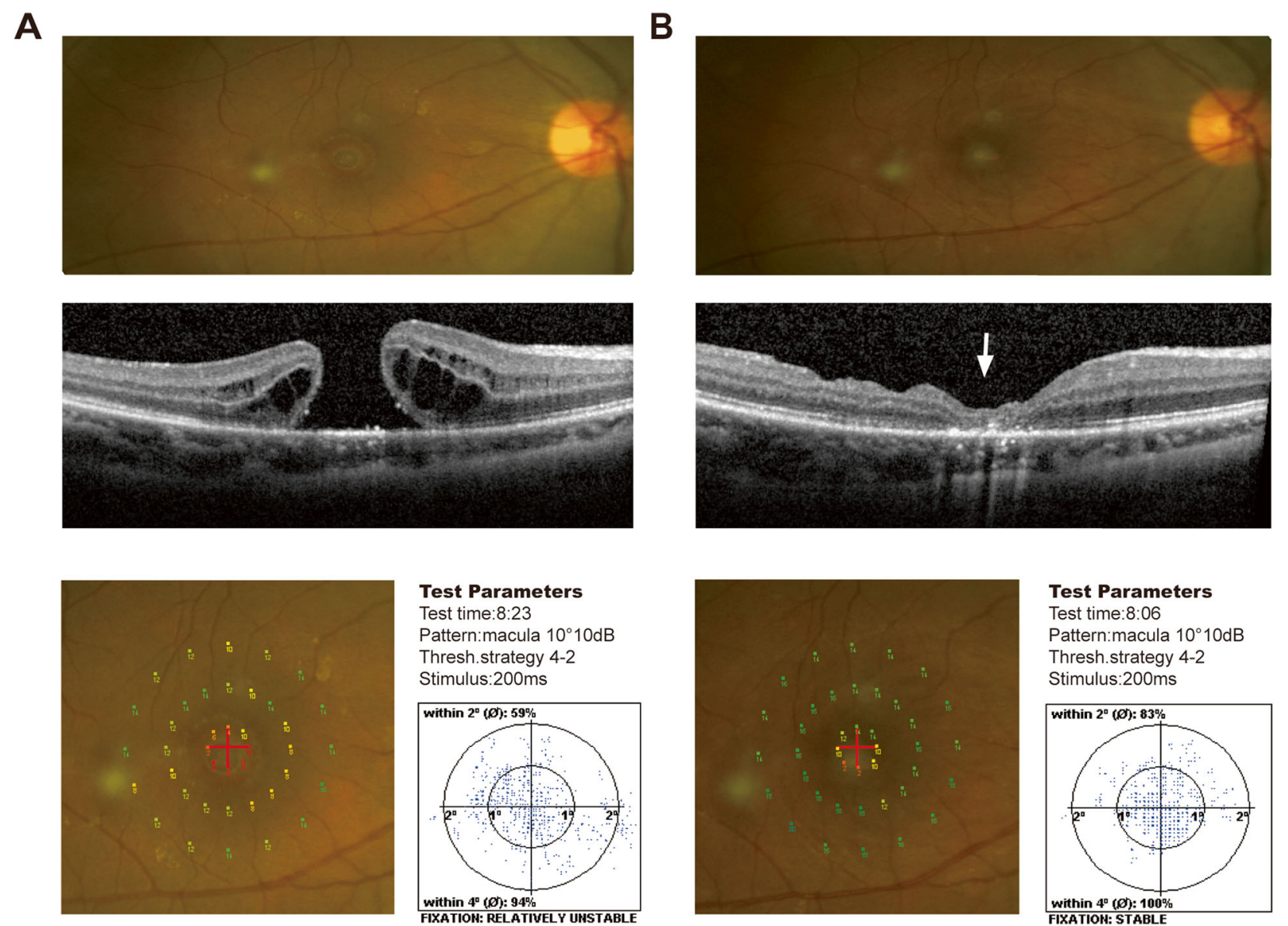

Fig. 1 Results of a large IMH patient at baseline (a) and 6 months after ILM tamponade surgery (b). SD-OCT showed the minimal diameter of the macular hole before surgery was $607 \mu \mathrm{m}$. The macular hole was close and filled with amorphous tissues at 6 months after surgery (white arrow). Microperimetry showed the improvement of overall macular sensitivity, especially foveal sensitivity, at 6 months postoperatively. The foveal fixation upgraded from relative unstable to stable. The fixation stability within $2^{\circ}$ increase from $59 \%$ at baseline to $83 \%$ at

6 months postoperatively

with vitrectomy. The relatively long duration of symptom in our study ( $7.77 \pm 3.09$ months) might also contribute to a more challenging situation of disease and a worse pre- and post-operative BCVA.

In addition to improving postoperative BCVA and favourable closure rates, this study introduced microperimetry for the evaluation of retinal function before and after ILM tamponade surgery for large macular holes. Although BCVA is recognized as a basic assessment for foveal function, it may underestimate functional recovery in patients who underwent macular holes surgeries because of possible change of fixation point [24]. Microperimetry has been applied to measure a point to point retinal sensitivity and fixation in various macular diseases $[25,26]$. A previous study about relatively smaller macular holes and recurrent macular holes evaluated the visual outcomes 1 year after ILM flap transposition. They suggested that besides BCVA, retinal sensitivity provides more specific functional information about the macula and better reflects the visual restoration after macular surgery [27]. There are potential concerns that the insertion of the ILM inside the macular hole may hinder the recovery of retinal function. For example, the ILM sheet may form a block that prevents the healing of the neurosensory retina and the reconstruction of photoreceptors, or the RPE may be damaged during the insertion procedure. In the present study, we recorded foveal (with $\left.2^{\circ}\right)$ and peri-foveal $\left(2^{\circ}\right.$ to $\left.10^{\circ}\right)$ macular sensitivity separately. According to the equipment and fundus structure, $1^{\circ}$ converts to $250 \mu \mathrm{m}$. The detection range of foveal sensitivity (within $2^{\circ}$ ) equals $500 \mu \mathrm{m}$, which represents the function over the area of the macular hole. We observed that the mean overall macular sensitivity increased from $8.58 \pm 3.05$ preoperatively to $11.55 \pm 2.72$ at 6 months after surgery. Additionally, the mean change in foveal sensitivity $(4.17 \pm 1.83 \mathrm{~dB})$ was greater than the change in peri-foveal sensitivity $(2.67 \pm$ 
Table 2 Linear regression analysis of 6-month postoperative logMAR BCVA with single variables (A); multiple linear regression model with backward stepwise method (B)

\begin{tabular}{|c|c|c|c|c|c|c|c|c|}
\hline \multirow[t]{2}{*}{ Variables } & \multicolumn{4}{|l|}{ (A) } & \multicolumn{4}{|l|}{$(B)^{*}$} \\
\hline & $\bar{B}$ & $\mathrm{Se}(B)$ & $P$-value & $95 \% \mathrm{Cl}$ & $\bar{B}$ & $\mathrm{Se}(B)$ & $P$-value & $95 \% \mathrm{Cl}$ \\
\hline Age (years) & 0.000 & 0.007 & 0.972 & -0.015 to 0.015 & -0.004 & 0.003 & 0.253 & -0.011 to 0.003 \\
\hline Gender & 0.013 & 0.157 & 0.935 & -0.315 to 0.340 & -0.079 & 0.081 & 0.342 & -0.252 to 0.093 \\
\hline Duration of symptom (months) & 0.063 & 0.017 & 0.001 & 0.028 to 0.098 & 0.011 & 0.014 & 0.455 & -0.020 to 0.042 \\
\hline MD of IMH ( $(\mu \mathrm{m})$ & 0.001 & 0.000 & 0.164 & 0.000 to 0.001 & 0.000 & 0.000 & 0.591 & -0.001 to 0.000 \\
\hline Pre logMAR BCVA & 0.770 & 0.110 & 0.000 & 0.541 to 0.999 & 0.290 & 0.188 & 0.145 & -0.112 to 0.692 \\
\hline \multicolumn{9}{|l|}{ Pre macular sensitivity (dB) } \\
\hline Peri-foveal $\left(2^{\circ}\right.$ to $\left.10^{\circ}\right)$ & -0.065 & 0.013 & 0.000 & -0.091 to -0.038 & -0.242 & 0.146 & 0.146 & -0.050 to 0.008 \\
\hline Foveal (within $2^{\circ}$ ) & -0.129 & 0.018 & 0.000 & -0.166 to -0.091 & -0.430 & 0.040 & 0.040 & -0.127 to -0.003 \\
\hline
\end{tabular}

Se $(B)=$ standard error of $B$ coefficient, $M D=$ minimum diameter, $\mathrm{IMH}=$ idiopathic macular hole, $\mathrm{BCVA}=$ best corrected visual acuity, logMAR = logarithm of the minimum angle of resolution, pre $=$ preoperative

${ }^{*}$ Adjusted $\mathrm{R}^{2}$ for variables listed: 0.786

$2.29 \mathrm{~dB})$. These results reveal that the improvement in microperimetry after surgery mainly occurred in the fovea, where the macular hole is located, and that the ILM tamponade technique may have an advantage in retinal function recovery. The exact mechanism of ILM flap tamponade in foveal functional recovery requires further investigation. One hypothesis is that the ILM pieces filled into the macular hole contain Müller cells and form a scaffold that stimulates long-lasting glial cell proliferation. Serveal previous studies also observed similar results after different macular hole surgery. Sborgia et al. reported that both central macular sensitivity (within $4^{\circ}$ ) and macular sensitivity (within $12^{\circ}$ ) significantly improved in large macular hole after treatment of inverted ILM flap technique [28]. Wang et al. recorded increase of macular hole sensitivity after successful ILM peeling surgery [29].

Fixation is another important macular functional parameter that reflects the resolution of scotoma after surgery in Microperimeter-1. When macular disease occurs, fixation spot could be spontaneously relocated outside the foveal range. A study illustrated that patients with IMHs always had paracentral fixation, which was located $2^{\circ}$ outside of the centre at the margin of the macular hole before surgery. After vitreoretinal surgery, an acceptable percentage of patients obtained stable or relative central fixation [30]. In our current study, similar stable fixation recovery was achieved. The average foveal fixation stability within $2^{\circ}$ of the centre increased from $65.64 \pm 17.28 \%$ preoperatively to $78.59 \pm$ $13.00 \%$, and 20 eyes (90.9\%) showed improved fixation stability at 6 months after surgery. It is reported that the closure of macular hole could result in restoration and reorganization of fixation [31]. These results suggest that macular function partially recovered after ILM tamponade in the macular hole.

Several studies have investigated possible predictors for visual acuity prognosis of IMHs surgery such as ellipsoid zone defect area [32], macular hole closure index (MHCI) [33] or diameter of macular holes [34]. Our results revealed that mean preoperative foveal sensitivity (within $2^{\circ}$ ) was independently associated with postoperative $\log$ MAR BCVA at 6 months after ILM flap tamponade for larger IMHs, whereas preoperative BCVA and mean preoperative peri-foveal sensitivity $\left(2^{\circ}\right.$ to $\left.10^{\circ}\right)$ were less predictive factors. Since foveal sensitivity (within $2^{\circ}$ ) represents the function over the area of the macular hole, a possible explanation for this finding may be attributed to the fact that eyes with better foveal sensitivity before surgery may reflect less damage of neurosensory retina within the area of macular hole and may therefore have a better recovery and visual outcomes after surgery. A previous report focused on macular hole surgery also found a closer connection between preoperative central macular sensitivity and postoperative visual recovery, which was consistent with our results on large IMHs [35]. These data indicate that preoperative foveal sensitivity is a better prognostic indicator than preoperative BCVA for IMHs.

\section{Conclusions}

Despite some limitations exist including a relatively small sample, relatively short follow-ups and lack of controls, this study reported that improvement in retinal sensitivity and fixation stability was achieved in large IMHs undergoing the free ILM flap tamponade technique and that preoperative foveal sensitivity may be an effective predictor of postoperative BCVA. In summary, microperimetry is a more precise measurement technique than BCVA for surgeons to follow-up retinal function in IMHs. ILM flap tamponade technique is helpful not only for macular hole closure but also for macular function recovery. 


\section{Supplementary information}

Supplementary information accompanies this paper at https://doi.org/10. 1186/s12886-020-01573-z.

\section{Additional file 1.}

\section{Abbreviations}

IMHs: Idiopathic macular holes; ILM: Internal limiting membrane; BCVA: Bestcorrected visual acuity; OCT: Optical coherence tomography; PPV: Pars plana vitrectomy; dB: Decibels; logMAR: Logarithm of the minimum angle of resolution; MD: Minimum diameter

\section{Acknowledgments}

The authors thank Wei Chen and Jian Sun for their vital assistance in microperimetry measurement.

\section{Authors' contributions}

JYF, PRH contributed to the study design and protocol. FEC performed the surgery. JYF, PRH and HW prepared and reviewed the manuscript. JQC, YFH and JRS collected the data. JYF and $\mathrm{HZ}$ did the statistical analysis of the data. All authors read and approved the final manuscript.

\section{Funding}

The study design and clinical data collection were supported by the Nationa Natural Science Foundation of China (No. 81500732). The statistical analysis was supported by the National Natural Science Foundation of China (No. 81700843). The imageological examination was supported by BethuneLangmu eye research fund for the young and middle-aged ophthalmologist (BJ-LM2018001J). The manuscript writing and polishing were supported by Shanghai Pujiang Program (No. 16PJ1408500).

\section{Availability of data and materials}

The datasets created during and/or analyzed during the current study available from the corresponding author on reasonable request.

\section{Ethics approval and consent to participate}

All surgeries and measurements performed in this study involving human participants were in accordance with ethical standards of the institutional and national research committee and Declaration of Helsinki. This study was approved by the ethics committee of Shanghai General Hospital. And all participants were informed about related issues of this study and signed informed consent.

\section{Consent for publication}

Not applicable.

\section{Competing interests}

The authors declare that they have no competing interests.

\section{Author details}

'Department of Ophthalmology, Shanghai General Hospital (Shanghai First People's Hospital), Shanghai Jiao Tong University School of Medicine, No.100 Hai Ning Road, Shanghai 200080, China. ${ }^{2}$ Shanghai Key Laboratory of Fundus Disease, Shanghai, China. ${ }^{3}$ Shanghai Engineering Center for Visual Science and Photomedicine, Shanghai, China.

\section{Received: 13 July 2019 Accepted: 16 July 2020}

Published online: 23 July 2020

\section{References}

1. Johnson RN, Gass JD. Idiopathic macular holes. Observations, stages of formation, and implications for surgical intervention. Ophthalmology. 1988;95(7):917-24.

2. Ho A, Guyer D, Fine S. Macular hole. Surv Ophthalmol. 1998;42(5):393-416

3. Ando F, Sasano K, Ohba N, Hirose H, Yasui O. Anatomic and visual outcomes after indocyanine green-assisted peeling of the retinal internal limiting membrane in idiopathic macular hole surgery. Am J Ophthalmol. 2004;137(4):609-14.

4. Jackson $\mathrm{TL}$, Donachie PHJ, Sparrow JM, Johnston RL. United Kingdom National Ophthalmology Database study of vitreoretinal surgery: report 2, macular hole. Ophthalmology. 2013;120(3):629-34
5. Kumagai K, Furukawa M, Ogino N, Uemura A, Demizu S, Larson E. Vitreous surgery with and without internal limiting membrane peeling for macular hole repair. Retina. 2004;24(5):721-7.

6. Madi HA, Masri I, Steel DH. Optimal management of idiopathic macular holes. Clin Ophthalmol. 2016;10:97-116.

7. Liu PK, Chang YC, Wu WC. Management of refractory macular hole with blood and gas-assisted autologous neurosensory retinal free flap transplantation: a case report. BMC Ophthalmol. 2018;18(1):230.

8. Chang YC, Liu PK, Kao TE, Chen KJ, Chen YH, Chiu WJ, Wu KY, Wu WC Management of refractory large macular hole with autologous neurosensory retinal free flap transplantation. Retina. 2019;00:1-6.

9. Tam ALC, Yan P, Gan NY, Lam WC. THE CURRENT SURGICAL MANAGEMENT OF LARGE, RECURRENT, OR PERSISTENT MACULAR HOLES. Retina. 2018; 38(7):1263-1275

10. Dai $Y$, Dong $F$, Zhang $X$, Yang $Z$. Internal limiting membrane transplantation for unclosed and large macular holes. Graefes Arch Clin Exp Ophthalmol. 2016:254(11):2095-9.

11. Park JH, Lee SM, Park SW, Lee JE, Byon IS. Comparative analysis of large macular hole surgery using an internal limiting membrane insertion versus inverted flap technique. Br J Ophthalmol. 2019;103(2):245-50.

12. Rohrschneider K, Springer C, Bultman S, Volcker HE. Microperimetrycomparison between the microperimeter 1 and the scanning laser ophthalmoscope-fundus perimetry. Am J Ophthalmol. 2005;139:125-34.

13. Palkovits S, Hirnschall N, Georgiev S, Leisser C, Findl O. Test-retest reproducibility of the microperimeter MP3 with fundus image tracking in healthy subjects and patients with macular disease. Transl Vis Sci Technol. 2018;7(1):17

14. Winterhalter S, Lux A, Maier AK, Schoz C, Heussen FM, Huber KK, Joussen AM. Microperimetry as a routine diagnostic test in the follow-up of retinal vein occlusion? Graefes Arch Clin Exp Ophthalmol. 2012;250(2):175-83.

15. Pearce E, Sivaprasad S, Chong NV. Factors affecting Reading speed in patients with diabetic macular edema treated with laser photocoagulation. PLoS One. 2014:9(9):e105696.

16. Yu Y, Liang X, Wang Z, Wang J, Liu W. Clinical and morphological comparisons of idiopathic macular holes between stage 3 and stage 4 . Graefes Arch Clin Exp Ophthalmol. 2018;256(12):2327-33.

17. Michalewska Z, Michalewski J, Adelman RA, Nawrocki J. Inverted internal limiting membrane flap technique for large macular holes. Ophthalmology. 2010;117(10):2018-25.

18. Andrew N, Chan WO, Tan M, Ebneter A, Gilhotra JS. Modification of the inverted internal limiting membrane flap technique for the treatment of chronic and large macular holes. Retina. 2015;36(4):834-7.

19. Morizane $Y$, Shiraga F, Kimura S, Hosokawa M, Shiode $Y$, Kawata T, Hosogi M, Shirakata Y, Okanouchi T. Autologous transplantation of the internal limiting membrane for refractory macular holes. Am J Ophthalmol. 2014; 157(4):861-9.

20. De Novelli FJ, Preti RC, Ribeiro Monteiro ML, Pelayes DE, Junqueira Nóbrega M, Takahashi WY. Autologous internal limiting membrane fragment transplantation for large, chronic, and refractory macular holes. Ophthalmic Res. 2015:55(1):45-52.

21. Park SW, Pak KY, Park KH, Kim KH, Byon IS, Lee JE. Perfluoro-n-octane assisted free internal limiting membrane flap technique for recurrent macular hole. Retina. 2015;35(12):2652-6.

22. Ramtohul P, Parrat E, Denis D, Lorenzi U. Inverted internal limiting membrane flap technique versus complete internal limiting membrane peeling in large macular hole surgery: a comparative study. BMC Ophthalmol. 2020;20(1):11

23. Yamashita $T$, Sakamoto $T$, Terasaki H, Iwasaki M, Ogushi $Y$, Okamoto $F$, Takeuchi M, Yasukawa T, Takamura Y, Ogata N. Nakamura Y; writing committee of Japan-clinical retina research team (J-CREST). Best surgical technique and outcomes for large macular holes: retrospective multicentre study in Japan. Acta Ophthalmol. 2018;96(8):e904-10.

24. Richter-Mueksch S, Vecsei-Marlovits PV, Sacu SG, Kiss CG, Weingessel B, Schmidt-Erfurth U. Functional macular mapping in patients with vitreomacular pathologic features before and after surgery. Am J Ophthalmol. 2007;144(1):23-31

25. Cassels NK, Wild JM, Margrain TH, Chong V Acton JH. The use of microperimetry in assessing visual function in age-related macular degeneration. Surv Ophthalmol. 2018;63(1):40-55.

26. Laishram M, Srikanth K, Rajalakshmi AR, Nagarajan S, Ezhumalai G. Microperimetry - a new tool for assessing retinal sensitivity in macular diseases. J Clin Diagn Res. 2017;11(7):NC08-11. 
27. Leisser C, Palkovits S, Hirnschall N, Ullrich M, Hienert J, Zwickl H, Georgiev S, Findl O. One-year results after internal limiting membrane flap transposition for surgical repair of macular holes with respect to Microperimetry. Ophthalmic Res. 2019;61:83-7.

28. Sborgia G, Niro A, Sborgia A, Albano V, Tritto T, Sborgia L, Pastore V, Donghia R, Giancipoli E, Recchimurzo N, Boscia F, Alessio G. Inverted internal limiting membrane-flap technique for large macular hole: a microperimetric study. Int J Retina Vitreous. 2019;5:44.

29. Wang Z, Qi Y, Liang X, Yu Y, Chen J, Wang J, Liu X, Liu W. MP-3 measurement of retinal sensitivity in macular hole area and its predictive value on visual prognosis. Int Ophthalmol. 2019;39(9):1987-94.

30. Amari F, Ohta K, Kojima H, Yoshimura N. Predicting visual outcome after macular hole surgery using scanning laser ophthalmoscope microperimetry. Br J Ophthalmol. 2001;85:96-8.

31. Tarita-Nistor L, González EG, Mandelcorn MS, Lillakas L, Steinbach MJ. Fixation stability, fixation location, and visual acuity after successful macular hole surgery. Invest Ophthalmol Vis Sci. 2009;50(1):84-9.

32. Chalam KV, Murthy RK, Gupta SK, Brar VS, Grover S. Foveal structure defined by spectral domain optical coherence tomography correlates with visual function after macular hole surgery. Eur J Ophthalmol. 2010;20(3):572-7.

33. Liu $P$, Sun $Y$, Dong $C$, Song $D$, Jiang $Y$, Liang J, Yin H, Li X, Zhao M. A new method to predict anatomical outcome after idiopathic macular hole surgery. Graefes Arch Clin Exp Ophthalmol. 2016;254(4):683-8.

34. Kadonosono K, Yabuki K, Nishide T, Uchio E, Marron JA. Measured visual acuity of fellow eyes as a prognostic factor in macular hole surgery. Am J Ophthalmol. 2003;135(4):493-8

35. Chen WC, Wang Y, Li XX. Morphologic and functional evaluation before and after successful macular hole surgery using spectral-domain optical coherence tomography combined with microperimetry. Retina. 2012;32(9): 1733-42.

\section{Publisher's Note}

Springer Nature remains neutral with regard to jurisdictional claims in published maps and institutional affiliations.

Ready to submit your research? Choose BMC and benefit from:

- fast, convenient online submission

- thorough peer review by experienced researchers in your field

- rapid publication on acceptance

- support for research data, including large and complex data types

- gold Open Access which fosters wider collaboration and increased citations

- maximum visibility for your research: over $100 \mathrm{M}$ website views per year

At $\mathrm{BMC}$, research is always in progress.

Learn more biomedcentral.com/submissions 